\title{
SEX OF NUCLEI IN OCULAR TISSUES*
}

\author{
BY \\ CHRISTOPHER PEDLER AND NORMAN ASHTON \\ Department of Pathology, Institute of Ophthalmology, University of London
}

BARR AND BERTRAM (1949), reporting their observations on small chromatin bodies lying adjacent to the large nucleoli in nerve cells of the cat, pointed out for the first time that these peculiar structures, known then as " nucleolar satellites", were related to the sex of the animal, being found frequently in the female and seldom in the male. It has since been shown that this chromatin mass, now renamed "sex chromatin", may readily be demonstrated in the nuclei of most tissues of the female, both human and animal (Barr and others, 1950 ; Graham and Barr, 1952; Prince, 1952 ; Moore and Barr, 1953, 1954 ; Emery and McMillan, 1954).

In nuclei of somatic cells other than those of neurones, the sex chromatin appears as a small hemispherical mass with its flat surface lying against the nuclear membrane. It stains well with basic dyes, but is most clearly demonstrated in Feulgen-stained preparations of female skin, where it may be observed in up to 70 per cent. of nuclei (Fig. 1). In the male similar intranuclear bodies may occasionally be seen, but rarely in more than 10 per cent. of nuclei, and these are probably unrelated to the sex chromatin.

Similar sex differences exist in the nuclei of neutrophil polymorphonuclears, as was first shown by Davidson and Smith (1954), who noted small drumstick projections arising from the nuclei of occasional polymorphonuclears in women. This appears to be a further variant of sex chromatin and they have found that sex determination from an ordinary blood-film examination is completely reliable.

The exact nature of the special chromatin mass in the female cell is not yet finally determined, but the simplest explanation is that it consists of the $\mathrm{XX}$ pair of chromosomes, which in combination are sufficiently large and morphologically typical to be distinct from particulate chromatin, whereas the $\mathrm{Y}$ chromosome is too small to render visible the $\mathrm{XY}$ pair of chromosomes in the male nucleus. The apparent existence of sex chromatin in a small proportion of male nuclei may possibly be accounted for by artefacts caused by coarse particles of chromatin, by indentations of the nuclear membrane, and by overlapping of nuclei. In any event, whatever the nature of the chromatin mass, it is now generally accepted that sections of unknown origin, as far as sex is concerned, may be accurately classified as female or male ;

-Received for publication March 7, 1955. 
the method has already been extensively used to determine the true chromosomal sex of pseudohermaphrodites (Moore and others, 1953; Barr and Hobbs, 1954; Barr, 1954; Hunter and others, 1954; Marberger and Nelson, 1954 ; Polani and others, 1954), and to study the origin of teratomata (Hunter and Lennox, 1954; Cruickshank, 1955), and it may prove of value in medico-legal work.

Although the morphology of the sex chromatin has been studied in many different tissues and in a wide variety of cell types, there have been no studies of this kind on the cell nuclei of ocular tissues. The observations recorded in this paper show that the sex difference in nuclear morphology is as much in evidence in the eye as elsewhere, and is most readily discernible in the epithelial cells of the cornea and ciliary body and in the ganglion cells of the retina.

\section{Material and Methods}

In this investigation various preparations of ocular tissues were examined for the presence of sex chromatin. The methods employed may be conveniently considered in three groups:

(I) Sections of Whole Eyes.-Sagittal sections of whole eyes, approximately 10 microns thick, were used, and, since paraffin embedding was found to produce distortion of the nuclear membranes, the majority were prepared in celloidin. Fixation and staining methods will be described in some detail, since those used were dependent for their success on relatively minor particulars.

Formol saline (10 per cent.) was used as the fixing agent, being found preferable to Zenker's fluid, which gives rise to artefacts in the form of mercuric precipitates. Several staining methods were employed: acid giemsa, iron haematoxylin, haematoxylin and eosin, Mallory's triple stain, and crystal violet all gave positive results, but none of these was as satisfactory as the histochemical technique of Feulgen. This was carried out in its original manner using undiluted Schiff's reagent, but the most important step appeared to be the hydrolysis, for if this was inadequate a uniform purple colour resulted with lack of intranuclear detail, whereas excessive hydrolysis tended to destroy the clarity of cellular outline. It is essential to use exactly normal hydrochloric acid freshly prepared for each batch of sections.

(2) Conjunctival Scrapings.-The scrapings were obtained in the usual way and were treated either by the Feulgen technique or the acid giemsa method (Bisset, 1950). Giemsa staining appeared to give more reliable results in the conjunctiva.

(3) Flat Corneal Preparations.-The method of Buschke and others (1943) for obtaining flat preparations of the rat cornea proved to be unsuitable for human eyes; we found, however, that a flat layer of epithelium could easily be obtained by sectioning frozen corneae. A meridional strip of cornea, about $4 \mathrm{~mm}$. wide, was placed, with its epithelial surface uppermost, on the stage of a freezing microtome and pressed flat with a piece of silicone-treated glass. The specimen was partially frozen and after removing the glass a section of about $\mathbf{3 0}$ microns was rapidly cut. Staining was then carried out as described for the first group.

\section{Observations and Results}

(1) All tissues in the sections of whole eyes were examined for the presence of sex chromatin, but nuclear counts were attempted only on the corneal epithelium. After initial staining difficulties had been overcome, it was 


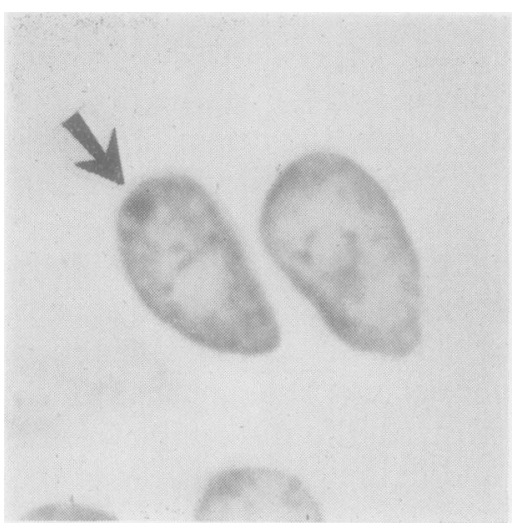

Fig. i.-Epithelial cells of eyelid. Feulgen stain. $\quad 1,270$.

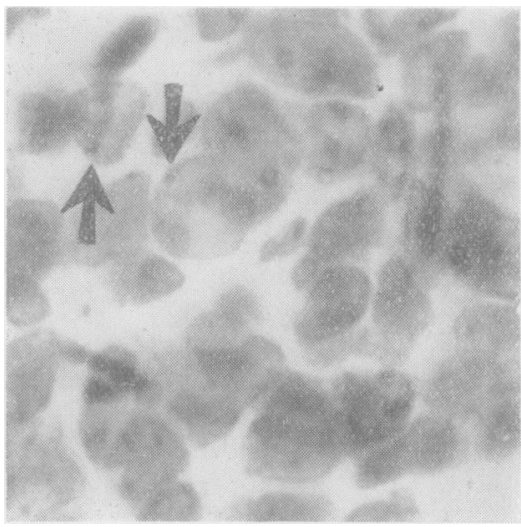

Fici. 3.- Retina. Cells of inner nuclear layer. Feulgen stain. $1,520$.

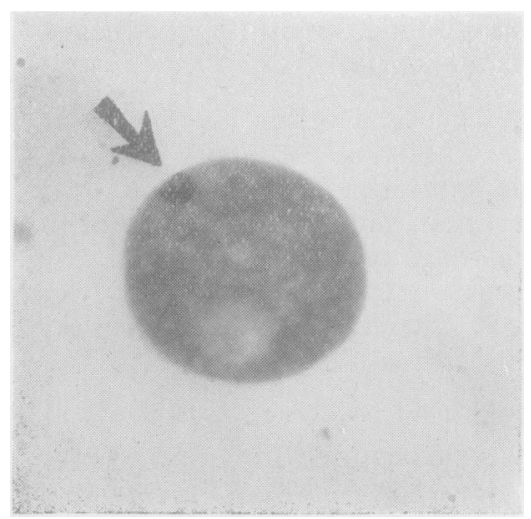

FIG. 5.-Epithelial cell in conjunctival scraping. Acid giemsa. $\times 2,400$.

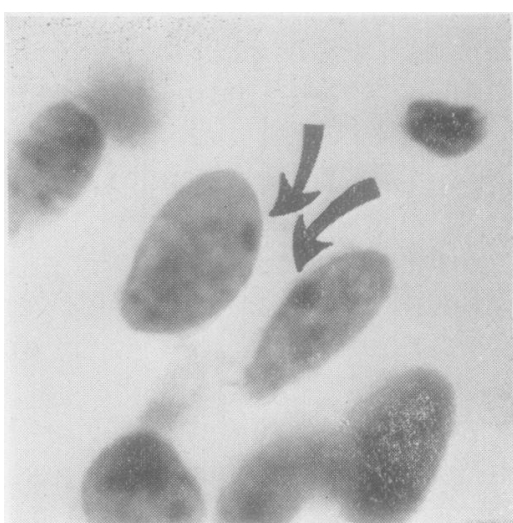

FIG. 2.-Epithelial cells of cornea. Feulgen stain. $\quad 1,380$.

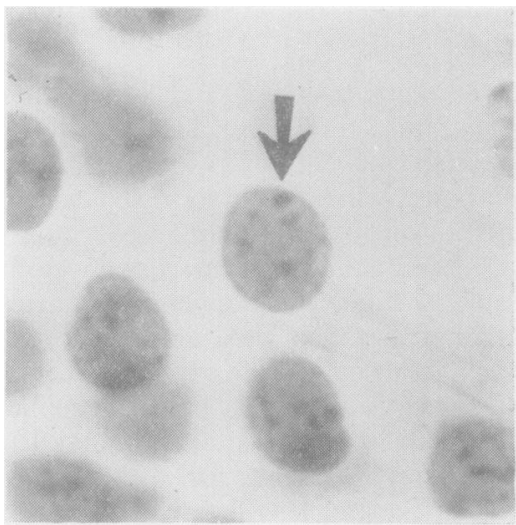

Fig. 4.--Retina. Ganglion cells at macula. Feulgen stain. $\times 1,600$.

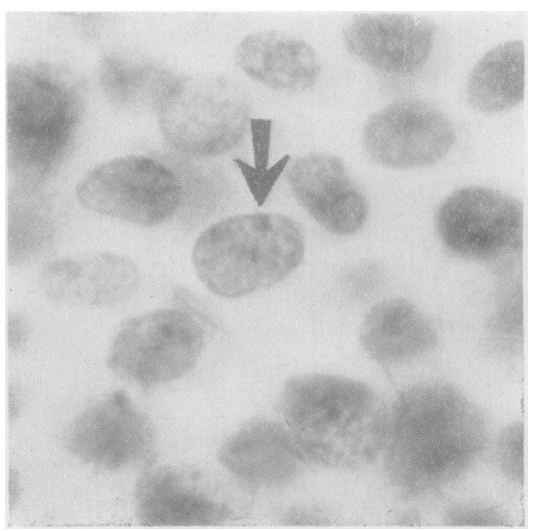

Fig. 6.-Epithelial cells in flat corneal preparation. Haematoxylin and eosin. $\times 1,270$. 
clear that some of the nuclei of the corneal epithelium in the female contained a structure not commonly present in the male. These bodies were similar in appearance and staining reactions to those described in other tissues of ectodermal origin, and consisted of a dense triangular or quadrilateral mass of Feulgen-positive material lying immediately adjacent to the nuclear membrane (Fig. 2). They were observed in cells at all levels but were most frequently found in the basal layer.

To record the percentage of nuclei containing these structures, 100 cells were counted in 100 sections and in every case the sex of the subject was unknown to the observer. Since cells containing sex chromatin appeared to occur in groups, ten separate fields, spread as evenly as possible over the extent of the epithelium, were examined.

Of the 100 cases studied, the sex was correctly determined in 92 , and the distribution of the incidence of sex chromatin in the nuclei is shown in Fig. 7. Of the remaining eight cases, four were unreadable owing to lack of definition and four were incorrectly sexed as females owing to the presence of an unusually high number of intranuclear structures, which on re-examination after greater experience, could be distinguished from sex chromatin.

The 92 cases correctly labelled consisted of equal numbers of males and females. In the 46 females the percentage of nuclei containing sex chromatin lay between 20 and 95 per cent., only one case being found at each

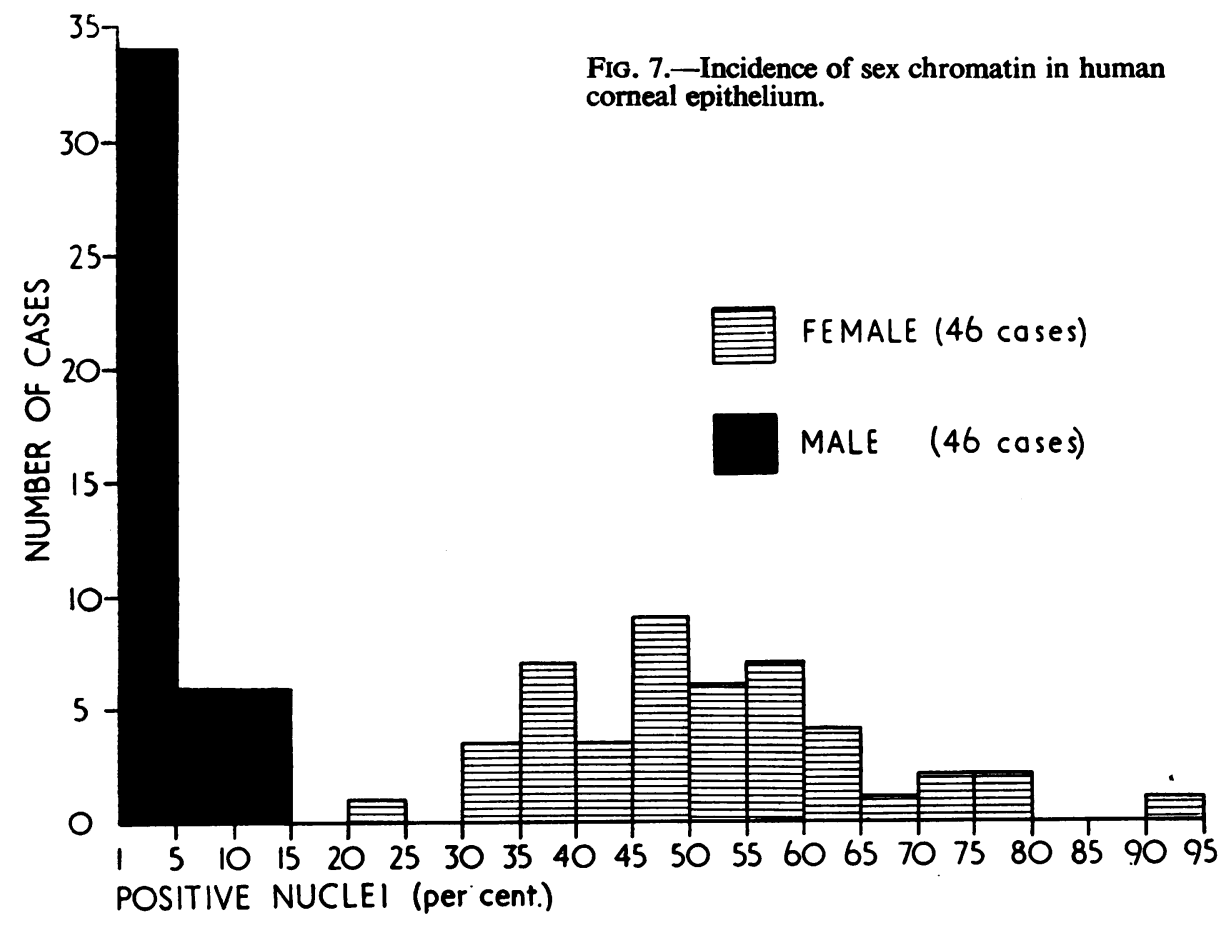


extreme, so that the vast majority lay between 30 and 80 per cent. All the 46 males showed structures resembling sex chromatin, but the incidence never exceeded 15 per cent. and in the majority (34) the incidence was less than 5 per cent.

Thus, with very few exceptions, the incidence of sex chromatin in the corneal epithelium of the female ranges from $30-80$ per cent. as compared to a range of $0-15$ per cent. in the male; these figures are similar to those obtained in investigations on the human epidermis (Emery and McMillan, 1954), and it is evident that sex may be determined as accurately in the corneal epithelium as in that of the skin.

In sections of the whole eye, sex chromatin was identified also in the following tissues :

(a) stromal cells of the iris,

(b) epithelium of the ciliary processes,

(c) stromal cells of the ciliary body,

(d) ganglion and nuclear cells of the retina (Figs 3 and 4).

The nuclei of the ganglion cells contained particularly clear sex chromatin masses (Fig. 4), whereas those in the cells of the nuclear layers were commonly obscured by numerous other granules of similar size. The other tissues mentioned contained intranuclear bodies of the same type as those found in the corneal epithelium.

(2) Smears of 25 conjunctival scrapings were examined for sex chromatin. None of the male nuclei was positive, but characteristic structures were seen in the female, which were similar in every way to those of the corneal epithelium, except that they occurred much less frequently (Fig. 5). In fact, only 3 per cent. of the female cells examined contained sex chromatin. The probable explanation of this low incidence is the fact that conjunctival scrapings tend to remove only the superficial layers so that the smears contain a very high proportion of degenerate and structureless cells.

(3) Flat corneal preparations were examined in order to determine whether this method was superior to transverse sections for demonstrating sex chromatin, and to discover whether positive nuclei did in fact occur in groups as had been thought earlier in this study. It was found that flat preparations had no particular advantage, for there was no evidence of grouping and the incidence of sex chromatin was the same as that recorded in transverse sections (Fig. 6).

\section{Summary}

(1) The recently discovered sex chromatin has now been identified in the nuclei of most tissues of the human and animal female.

(2) In this investigation sex chromatin was sought in ocular tissues: celloidin sections of the whole eye, conjunctival scrapings, and flat corneal preparations. The methods employed are described in detail. 
(3) Structures identified as the female sex chromatin were found in conjunctival, ciliary, and corneal epithelium, in stromal cells of the iris and ciliary body, in the nuclear layers of the retina, and in the ganglion cells where the chromatin masses were particularly well defined.

(4) In the cornea the distribution of the incidence of sex chromatin was determined, and the figures obtained were similar to those reported for the human epidermis.

(5) Of 100 corneal sections examined, the sex was correctly ascertained in 92 , four being unreadable, and four obscured by artefact. It is evident that sex may be determined as accurately in the epithelium of the cornea as in that of the skin.

Our thanks are due to Mr. A. McNeil for technical assistance, and to the Medical Illustration Department for the photographs.

\section{REFERENCES}

BARR, M. L. (1954). Surg. Gynec. Obstet., 99, 184. and BERTRAM, E. G. (1949). Nature (Lond.), 163, 676.

, Bertram, L. F., and LindSAy, H. A. (1950). Anat. Rec., 107, 283. and HoBBs, G. E. (1954). Lancet, 1, 1109.

Bisset, K. A. (1950). "The Cytology and Life-History of Bacteria", p. 6, Livingstone, Edinburgh. Buschke, W., Friedenwald, J. S., and Fleischmann, W. (1943). 'Bull. Johns Hopk. Hosp. 73, 143.

CruickSHANK, B. B. (1955). Lancet, 1, 253.

DAvidson, W. M., and Smirth, D. R. (1954). Brit. med. J., 2, 6.

EMRRY, J. L., and MCMILLAN, M. (1954). J. Path. Bact., 68, 17.

GraHAM, M. A., and BARR, M. L. (1952). Anat. Rec., 112, 709.

HuNTER, W. F., and LENNOX, B. (1954). Lancet, 2, 633. , Lennox, B., and Pearson, M. G. (1954). Ibid., 1, 372.

MARberger, E., and Nelson, W. O. (1954). J. clin. Endocr., 14, 768.

MOORE, K. L., and BARR, M. L. (1953). J. comp. Neurol., 98, 213.

-, GrahaM, M. A., and BARR, M. L. (1953). Surg. Gynec. Obstet. 96, 641.

Polani, P. E., Hunter, W. F., and Lennox, B. (1954). Lancet, 2, 120.

PrInCE, R. H. (1952). "Sex and the Cell Nucleus". M.Sc. Thesis, University of Western Ontario. 